\title{
Low Field Magnetic Properties of FeCo-Based Alloys
}

\author{
M. Hasiak ${ }^{a, *}$, M. Miglierini ${ }^{b, c}$, A. Łukiewska ${ }^{d}$, J. KAleta $^{a}$, J. ZBroszCZYK $^{d}$ \\ ${ }^{a}$ Institute of Materials Science and Applied Mechanics, Wrocław University of Technology, Smoluchowskiego 25, 50 \\ 370 Wrocław, Poland \\ ${ }^{b}$ Institute of Nuclear and Physical Engineering, Faculty of Electrical Engineering and Information Technology, \\ Slovak University of Technology in Bratislava, Ilkovičova 3, 81219 Bratislava, Slovakia \\ ${ }^{c}$ Regional Centre of Advanced Technologies and Materials, Palacky University, 17. listopadu 12, 77146 Olomouc, \\ Czech Republic \\ ${ }^{d}$ Institute of Physics, Częstochowa University of Technology, 42200 Częstochowa, Poland
}

\begin{abstract}
Low field magnetic properties of amorphous $\left(\mathrm{Fe}_{x} \mathrm{Co}_{1}\right)_{76} \mathrm{Mo}_{8} \mathrm{Cu}_{1} \mathrm{~B}_{15}$ alloys $(x=3,6$ and 9$)$ were characterized by magnetic after-effect and initial magnetic susceptibility. Activation energies and pre-exponential factors of the Arrhenius law that were derived from the disaccommodation curves are of about $1.188 \mathrm{eV}$ and $10^{-15} \mathrm{~s}$, respectively. Local magnetic arrangement was investigated by ${ }^{57} \mathrm{Fe}$ Mössbauer spectrometry. The average hyperfine magnetic field decreases with increasing Fe/Co ratio due to smaller relative contribution of cobalt. The overall magnetic parameters of the alloy prove its good soft magnetic properties with an application potential.
\end{abstract}

DOI: 10.12693 /APhysPolA.126.118

PACS: 76.80.+y, 75.50.Kj, 75.60.Lr, 71.55.Jv

\section{Introduction}

Excellent soft magnetic properties of metallic glasses that could provide nanocrystalline alloys are frequently investigated. Along with classical compositions [1], novel structures containing Mo [2], Co [3], or more recently also combination of these two [4], are of close interest. Partial replacement of Fe atoms by $\mathrm{Co}$ in such alloys leads to both, changes in the structure, and to the increase of magnetic inductions at elevated temperatures. Employing Mössbauer spectrometry, behaviour of metallic glasses can be studied also at elevated temperatures [5]. The aim of this paper is to study low field magnetic properties of amorphous FeCo-based alloys containing Mo with varying $\mathrm{Fe} / \mathrm{Co}$ ratio.

\section{Experimental details}

$\left(\mathrm{Fe}_{x} \mathrm{Co}_{1}\right)_{76} \mathrm{Mo}_{8} \mathrm{Cu}_{1} \mathrm{~B}_{15}(x=3,6,9)$ metallic glasses were prepared by rapid quenching. The amorphicity of the alloys was checked at room temperature by Xray diffractometry and ${ }^{57} \mathrm{Fe}$ Mössbauer spectroscopy in transmission geometry. The initial magnetic susceptibility was measured for toroidal samples in AC magnetizing field with frequency of $2 \mathrm{kHz}$ by means of a completely automated set-up.

\section{Results and discussion}

Magnetic characterization was done by investigating the initial magnetic susceptibility $\left(\chi_{2}\right)$ and the magnetic

*corresponding author; e-mail: Mariusz.Hasiak@pwr.wroc.pl after-effect $(\Delta(1 / \chi))$. The highest value of the initial magnetic susceptibility at room temperature is found for $x=9$ (Fig. 1). With decreasing $x$, an increase in transformation temperature from ferro- to paramagnetic state (the Curie temperature of the amorphous matrix, $T_{C}$ ) was observed. Moreover, $\chi_{2}$ values for the $x=3$ sample are not constant below $T_{C}$ like for the other two compositions.

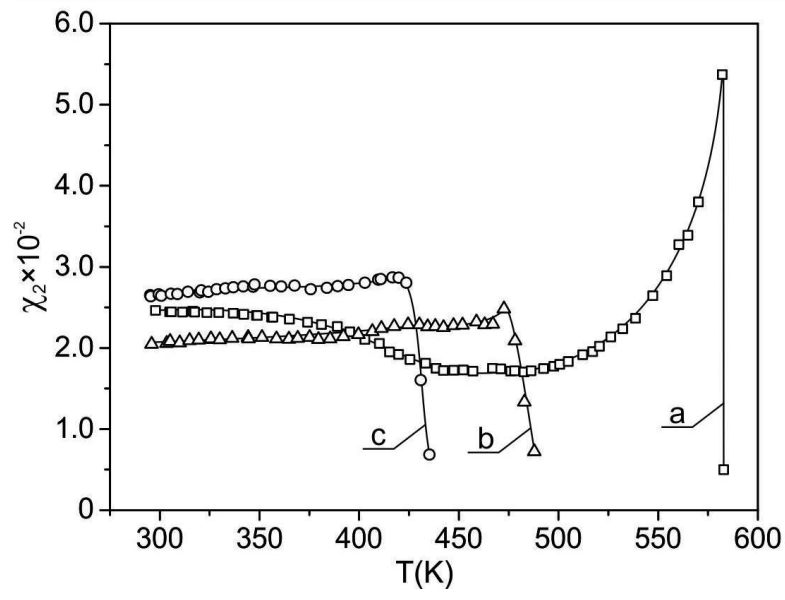

Fig. 1. The initial magnetic susceptibility $\chi_{2}$ plotted against temperature $T$ for the as-quenched $\left(\mathrm{Fe}_{x} \mathrm{Co}_{1}\right)_{76} \mathrm{Mo}_{8} \mathrm{Cu}_{1} \mathrm{~B}_{15}$ for $x=3$ (a), $x=6$ (b) and $x=9$ (c).

The magnetic after-effect was derived from decomposition of isochronal disaccommodation curves that were obtained as follows: $\Delta(1 / \chi)=1 / \chi_{2}-1 / \chi_{1}$. Here $\chi_{1}$ and $\chi_{2}$ are initial susceptibilities measured at the times $t_{1}=2 \mathrm{~s}$ and $t_{2}=120 \mathrm{~s}$ after demagnetization. Temperature dependence of isochronal disaccommodation, which 
is presented in Fig. 2, was analyzed in the temperature range $(300-500 \mathrm{~K})$.

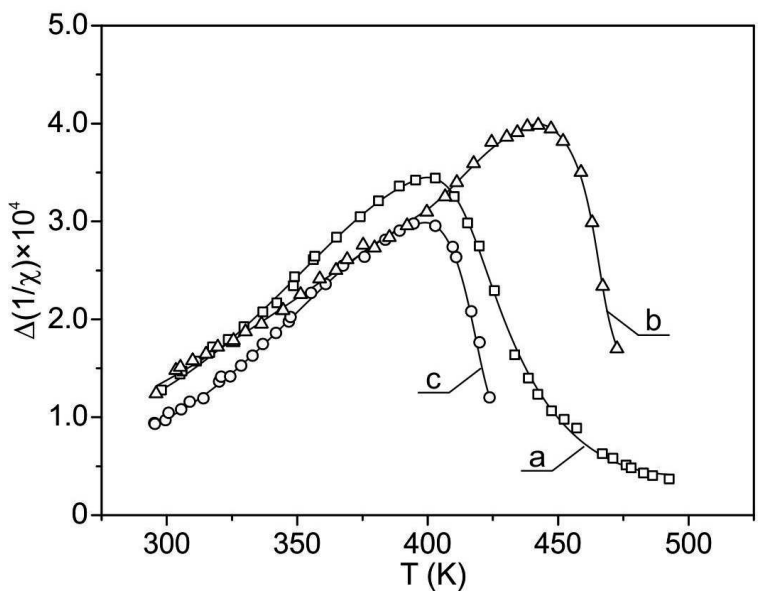

Fig. 2. The isochronal disaccommodation $\Delta(1 / \chi)$ plotted against temperature $T$ for amorphous $\left(\mathrm{Fe}_{x} \mathrm{Co}_{1}\right)_{76} \mathrm{Mo}_{8} \mathrm{Cu}_{1} \mathrm{~B}_{15}$ for $x=3$ (a), $x=6$ (b), and $x=9$ (c).

Using gaussian distributions of $\ln \tau(\tau-$ relaxation times), the values of activation energies and preexponential factors of the Arrhenius law were calculated. The isochronal disaccomodation curves were deconvoluted into three elementary processes and the resulting parameters are listed in Table I.

TABLE I

The activation energy $(E)$ and pre-exponential factor of the Arrhenius law $(\tau)$ obtained for $\left(\mathrm{Fe}_{x} \mathrm{Co}_{1}\right)_{76} \mathrm{Mo}_{8} \mathrm{Cu}_{1} \mathrm{~B}_{15}(x=3,6,9)$ alloy.

\begin{tabular}{c|c|c|c}
\hline \hline sample & process & $\mathrm{E}(\mathrm{eV})$ & $\tau(\mathrm{s}) \times 10^{15}$ \\
\hline \multirow{2}{*}{$\left(\mathrm{Fe}_{3} \mathrm{Co}_{1}\right)_{76} \mathrm{Mo}_{8} \mathrm{Cu}_{1} \mathrm{~B}_{15}$} & I & 1.151 & 1.23 \\
\cline { 2 - 4 } & II & 1.213 & 2.96 \\
\cline { 2 - 4 } & III & 1.288 & 2.45 \\
\hline \multirow{3}{*}{$\left(\mathrm{Fe}_{6} \mathrm{Co}_{1}\right)_{76} \mathrm{Mo}_{8} \mathrm{Cu}_{1} \mathrm{~B}_{15}$} & I & 1.115 & 4.85 \\
\cline { 2 - 4 } & II & 1.272 & 3.34 \\
\cline { 2 - 4 } & III & 1.390 & 5.50 \\
\hline \multirow{2}{*}{$\left(\mathrm{Fe}_{9} \mathrm{Co}_{1}\right)_{76} \mathrm{Mo}_{8} \mathrm{Cu}_{1} \mathrm{~B}_{15}$} & I & 0.973 & 3.18 \\
\cline { 2 - 4 } & II & 1.086 & 2.51 \\
\cline { 2 - 4 } & III & 1.203 & 5.05
\end{tabular}

Room temperature Mössbauer spectra in Fig. 3 exhibit broad sextuplet-like absorption lines which are characteristic for amorphous structural arrangement. The associated distributions of hyperfine magnetic fields $P(B)$ demonstrate structural differences among the investigated samples, that stem from different $\mathrm{Fe} / \mathrm{Co}$ ratio. Subsequent deviations in chemical and/or topological short-range order of the resonant ${ }^{57} \mathrm{Fe}$ nuclei resulted in the average hyperfine magnetic fields of 19.00, 16.25, and 14.80 T for $x=3,6$, and 9 , correspondingly. They were derived from the $P(B)$ distributions with the accuracy of $\pm 0.06 \mathrm{~T}$.

It is noteworthy that the average hyperfine magnetic field decreases with $x$, i.e. with decreasing relative contribution of $\mathrm{Co}$, which has a higher magnetic moment than $\mathrm{Fe}$.
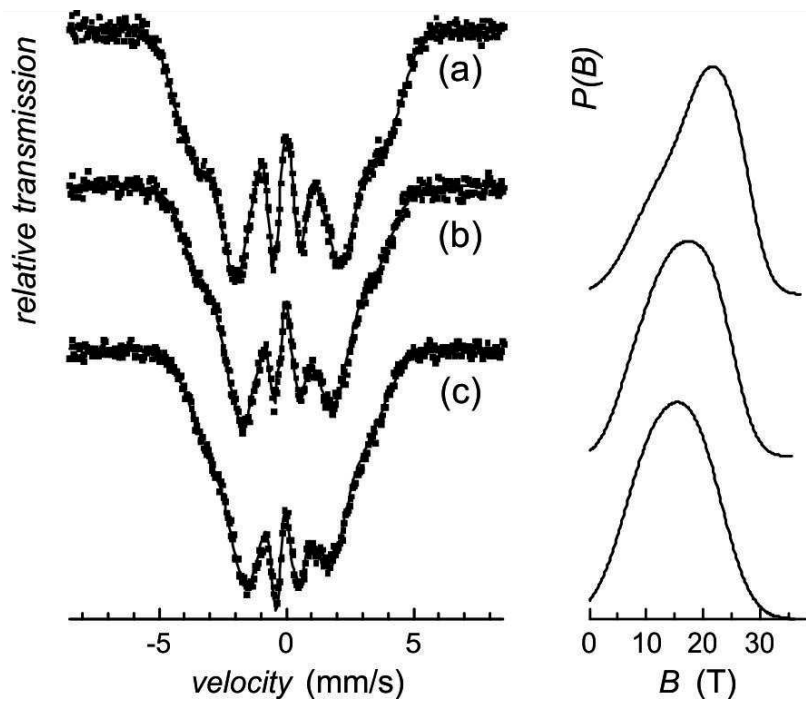

Fig. 3. Mössbauer spectra (left) and corresponding $P(B)$ distributions (right) of the $\left(\mathrm{Fe}_{x} \mathrm{Co}_{1}\right)_{76} \mathrm{Mo}_{8} \mathrm{Cu}_{1} \mathrm{~B}_{15}$ alloy for $x=3$ (a), $x=6$ (b), and $x=9$ (c).

\section{Conclusions}

We have investigated magnetic properties of $\left(\mathrm{Fe}_{x} \mathrm{Co}_{1}\right)_{76} \mathrm{Mo}_{8} \mathrm{Cu}_{1} \mathrm{~B}_{15}(x=3,6,9)$ metallic glasses. Activation energies and pre-exponential factors of the Arrhenius law that were derived from the disaccommodation curves are of about $1.188 \mathrm{eV}$ and $10^{-15} \mathrm{~s}$, respectively. The overall magnetic parameters of the alloy prove its good soft magnetic properties with a potential for applications.

\section{Acknowledgments}

This work was partially supported by the grants SKPL-0032-12, VEGA 1/0286/12, CZ.1.05/2.1.00/03.0058, and CZ.1.07/2.3.00/20.0155.

\section{References}

[1] I. Škorvánek, M. Miglierini, P. Duhaj, Mater. Sci. Forum 235-238, 771 (1997).

[2] B. Idzikowski, J. Baszyński, I. Škorvánek, K.H. Müller, D. Eckert, J. Magn. Magn. Mater. 177181, 941 (1998).

[3] M.A.Willard, D.E. Laughlin, M.E. McHenry, J. Appl. Phys. 87, 7091 (2000).

[4] C.F. Conde, J.M. Borrego, J.S. Blázquez, A. Conde, P. Švec, D. Janičkovič, J. Alloys Comp. 509, 1994 (2011).

[5] M. Miglierini, J.-M. Grenèche, J. Phys.: Condens. Matter. 15, 5637 (2003).

[6] W.H. Ciurzyńska, L.K. Varga, J. Olszewski, J. Zbroszczyk, M. Hasiak, J. Magn. Magn. Mater. 208, 61 (2000). 